\title{
Activity of Different Classes of Neurons of the Motor Cortex during Locomotion
}

\author{
Irina N. Beloozerova, ${ }^{1}$ Mikhail G. Sirota, ${ }^{1}$ and Harvey A. Swadlow ${ }^{2}$ \\ ${ }^{1}$ Barrow Neurological Institute, St. Joseph's Hospital and Medical Center, Phoenix, Arizona 85013, and 2Department of Psychology, University of \\ Connecticut, Storrs, Connecticut 06269
}

This study examines the activity of different classes of neurons of the motor cortex in the rabbit during two locomotion tasks: a simple (on a flat surface) and a complex (overstepping a series of barriers) locomotion. Four classes of efferent neurons were studied: corticocortical (CC) neurons with ipsilateral projection (CCIs), those with contralateral projection (CCCs), descending corticofugal neurons of layer $\mathrm{V}$ (CF5s), and those of layer VI (CF6s). In addition, one class of inhibitory interneurons (SINs) was investigated. CF5 neurons and SINs were the only groups that were strongly active during locomotion. In most of these neurons a clear-cut modulation of discharge in the locomotion rhythm was observed. During simple locomotion, CF5s and SINs were preferentially active in opposite phases of the step cycle, suggesting that SINs contribute to formation of the step-related pattern of CF5s. Transition from simple to complex locomotion was associated with changes of the discharge pattern of the majority of CF5 neurons and SINs. In contrast to CF5 neurons, other classes of efferent neurons (CCI, CCC, CF6) were much less active during both simple and complex locomotion. That suggests that CC interactions, both within a hemisphere (mediated by CCIs) and between hemispheres (mediated by CCCs), as well as corticothalamic interactions via CF6 neurons are not essential for motor coordination during either simple or complex locomotion tasks.

Key words: motor cortex; corticocortical neurons; corticothalamic neurons; interneurons; locomotion; rabbit

\section{Introduction}

Pyramidal tract neurons have been the focus of many studies of the activity of motor cortex during motor tasks (Porter and Lewis, 1975; Evarts and Tanji, 1976; Matsunami and Hamada, 1981; Evarts et al., 1983; Fromm, 1983; Armstrong and Drew, 1984a; Schmied and Fetz, 1987; Drew, 1993; Baker et al., 1999). Motor cortical neurons that project to other centers have received much less attention, however, despite the fact that communication between motor centers is believed to be essential for normal motor behavior. So far, only the activity of corticoreticular neurons during locomotion (Kably and Drew, 1998) and the activity of corticorubral (Fromm, 1983) and corticostriatal neurons (Bauswein et al., 1989; Turner and DeLong, 2000) during arm movements has been examined. The goal of the present study was to examine the activity of other classes of motor cortical neurons during locomotion, including several classes of efferent neurons and one class of interneurons. Such data are necessary for a better understanding of communications between motor cortex and other centers and for obtaining a better insight into the functions of intracortical circuits during movements.

The experiments were performed on fully awake rabbits, where several groups of neurons in sensory and motor cortical areas have been identified previously and their response properties extensively studied in the resting state (Swadlow, 1988, 1989, $1990,1991,1994)$. The activity of the following classes of neurons in the motor cortex was investigated for the first time during a

\footnotetext{
Received May 14, 2002; revised Nov. 19, 2002; accepted Nov. 20, 2002.

This work was supported by National Institutes of Health Grants F32 NS-10314 and R01 NS-39340 (I.N.B.) and MH-64024 (H.A.S.).

Correspondence should be addressed to Dr. Irina Beloozerova, Neurobiology, Barrow Neurological Institute, St. Joseph's Hospital and Medical Center, 350 West Thomas Road, Phoenix, AZ 85013. E-mail: ibelooz@chw.edu. Copyright $\odot 2003$ Society for Neuroscience $\quad 0270-6474 / 03 / 231087-11 \$ 15.00 / 0$
}

motor behavior (Fig. 1): (1) corticocortical (CC) neurons with ipsilateral projection (CCIs), (2) CC neurons with contralateral projection (CCCs), (3) descending corticofugal neurons of layer VI (CF6s) that project to the ventrolateral thalamus, and (4) a subpopulation of putative inhibitory interneurons (SINs). In addition, we studied descending corticofugal neurons of layer $\mathrm{V}$ (CF5s), and used this well studied population as a reference against which we compared the activity of the above populations.

The animals performed two locomotor tasks: (1) locomotion on a flat surface (a "simple" locomotion) and (2) locomotion with overstepping a series of barriers (a "complex" locomotion). During complex locomotion, visual recognition of the barriers and visuomotor coordination were necessary for successful negotiation of the barriers. It has been demonstrated previously that complex locomotion does require participation of the motor cortex, whereas simple locomotion does not (Trendelenberg, 1911; Liddell and Phillips, 1944; Beloozerova and Sirota, 1993). Thus, by comparing the activities of cortical neurons in these two locomotor tasks, one can estimate a contribution of the motor cortex to the control of complex locomotion.

We here report dramatic differences in the activity of different efferent subpopulations during locomotion and discuss their roles in transmitting cortical signals to other centers as well as a potential role of inhibitory interneurons in shaping the locomotion-related activity of efferent neurons. Some of the results have been published previously in abstract form (Beloozerova et al., 1998, 1999).

\section{Materials and Methods}

Recordings were obtained from the forelimb representation of the motor cortex of five awake adult Dutch-Belted rabbits. Some of the methods have been described previously (Swadlow, 1991; Beloozerova and Sirota, 1993; Swadlow et al., 1998) and will be reported briefly here. All experi- 


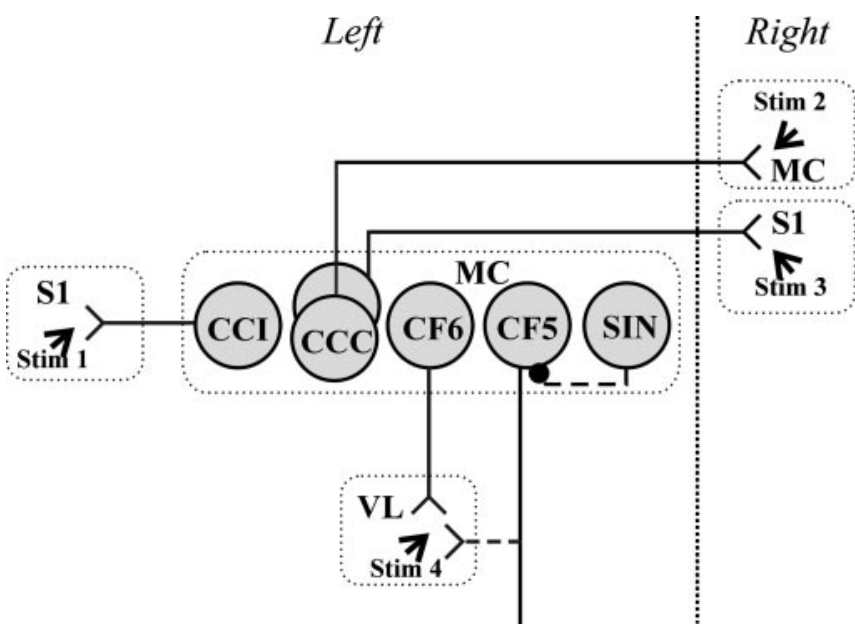

Figure 1. Types of neurons that were recorded in the forelimb representation of the left motor cortex (MC): CCls [corticocortical neurons projecting to the ipsilateral primary somatosensory cortex (S1)], CCCs (corticocortical neurons projecting to the contralateral motor cortex or primary somatosensory cortex), CF6s [corticofugal neurons of layer VI projecting to ventrolateral thalamus (VL)], and CF5s (corticofugal neurons of layer V). These neuron types were identified by their antidromic responses to electrical stimulation of the corresponding structures (Stim 1 to Stim 4). SINs were identified by their high-frequency orthodromic responses to stimulation of ventrolateral thalamus or a cortical site (Stim 1 to Stim 4). Solid lines indicate the directly tested projections; dotted lines show supposed projections.

ments were conducted with the approval of the University of Connecticut Animal Care and Use Committee.

Experimental design. Positive reinforcement (food) was used to adapt rabbits to the experimental situation and to engage them in locomotion behavior (Pryor, 1975). A box ( $2.5 \mathrm{~m}$ long and $0.5 \mathrm{~m}$ wide) served as an experimental chamber. A longitudinal wall divided the box into two corridors that rabbits passed sequentially and repeatedly. In one of the corridors, the floor was flat; in the other, five barriers $(4.5 \mathrm{~cm}$ high and 2 $\mathrm{cm}$ thick) were placed $43 \mathrm{~cm}$ apart. The passage of the subject through the beginning or the end of each corridor was monitored using infrared photodiodes.

General surgical procedures. After rabbits were trained, surgery was performed under pentobarbital sodium anesthesia (initial dose, 25-35 $\mathrm{mg} / \mathrm{kg}$ ) using aseptic procedures. The skin and fascia were removed from much of the dorsal surface of the rabbit's skull. Bones of the dorsal surface of the skull were fused together with stainless-steel screws and acrylic cement. An aluminum circular base was cemented to the screws. Later, awake rabbits were rigidly held by this base during mapping procedures and during identification of neurons before testing their activity in locomotion tasks. A portion of the skull over the approximate locations of the motor and the primary somatosensory limb representations was mechanically thinned to $\sim 0.3 \mathrm{~mm}$. This allowed an easy removal of the remaining thinned bone over an area of 100-200 $\mu \mathrm{m}$ in diameter before inserting a recording or a stimulation electrode into the cortex in awake animals.

Identifying the region of motor cortex. Motor cortex was identified in awake animals (after several days of a postoperative recovery period) by first localizing the forepaw representation of the primary somatosensory cortex using multiple-unit receptive field mapping procedures (Gould, 1986; Swadlow, 1990). During mapping, microelectrode penetrations were made 300-1000 $\mu \mathrm{m}$ apart with a tungsten-varnish insulated electrode [50 $\mu \mathrm{m}$ outer diameter (OD)]. Somatosensory receptive fields and effects of microstimulation were examined in layer IV of the primary somatosensory cortex and in layer $\mathrm{V}$ of the motor cortex. The forelimb area of the motor cortex (Fig. $2 \mathrm{~B}, 1$ ) was found on the rostral-medial border of the forelimb representation of the primary somatosensory cortex (Fig. $2 B, 2 a$ ). Here, cells responded only to deep manipulations of the limb (joints and/or muscles), and microstimulation (trains of five 50$100 \mu \mathrm{A}$ cathodal pulses at $100 \mathrm{~Hz}$ ) resulted in movements of the limb.

Implantation of stimulating electrodes. Stimulating electrodes were
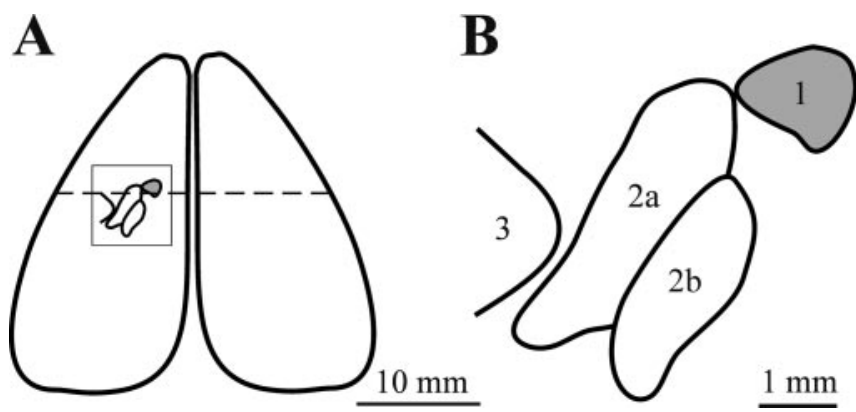

Figure 2. Location of the motor limb representation in the rabbit (a typical example). A, Schematic drawing of the hemispheres (dorsal view) and the limb representations. The dashed horizontal line indicates the zero anteroposterior coordinate. The square area shown in $A$ is represented in $B$ with a higher magnification to show the relative positions of motor representation of the forelimb (1), the primary somatosensory representations of the forelimb (2a) and the hindlimb (2b), as well as that of the whiskers (3).

constructed of platinum-iridium wire (140 $\mu \mathrm{m}$ OD) insulated with Teflon to within $0.4 \mathrm{~mm}$ of the tip. For the identification of CCIs, two stimulating electrodes were implanted into the ipsilateral primary somatosensory area $1 \mathrm{~mm}$ apart (Fig. 1, Stim 1). For the identification of CCCs, two stimulating electrodes were implanted into the contralateral motor cortex, also $1 \mathrm{~mm}$ apart, and two similarly spaced electrodes were implanted into the contralateral primary somatosensory cortex, both into the forelimb representations (Fig. 1, Stim 2, Stim 3). In the ipsilateral as well as in the contralateral primary somatosensory cortex, stimulating electrodes were implanted into the arm and forearm but not in the digits representations. For the identification of CF5s and CF6s, two or three stimulating electrodes were implanted in the ventrolateral thalamus (Fig. 1, Stim 4). In all cases, the electrodes were implanted after mapping the area by multiple-unit recording procedures.

Single-unit recording and neurons sampled. At the beginning of an experiment, a rabbit was positioned on a table, and the base that was attached to the skull during surgery was fixed in a frame, so the head of the rabbit was immobilized while the body was put in a comfortable position. Methods ensuring the humane treatment of subjects during immobilization of the head have been described previously (Swadlow, 1988, 1989, 1990, 1991; Beloozerova and Sirota, 1993). Neuronal activity was recorded extracellularly using platinum-tungsten quartz-insulated microelectrodes ( $40 \mu \mathrm{m}$ OD) pulled to a fine tip and mechanically sharpened using a diamond grinding wheel (Reitboeck, 1983). These electrodes were inserted into the motor cortex through small holes in the skull (100-200 $\mu \mathrm{m}$ in diameter) and intact dura. A manual single-axis micromanipulator (dimensions $2 \times 3 \times 10 \mathrm{~mm}$ ) rigidly fixed to the skull was used to lower the electrode. Unit data were collected and displayed using a commercially available data acquisition package (Datawave's Discovery and Experimenter's Workbench). Spikes were digitized at $30 \mathrm{kHz}$ and time-stamped at $0.1 \mathrm{msec}$. To aid in the identification of single neurons, a Spike Sort program was used to discriminate and identify the waveform of spikes of the neuron based on the extracted waveform parameters. The combinations of these parameters ("clusters") was used to distinguish different waveforms. After a neuron was isolated and identified, the head of the rabbit was released from the restrainer and the rabbit was placed in the experimental chamber. The activity of the neuron was then recorded during simple and complex locomotion.

Monitoring stepping movements. The duration of the stance and swing phases of the forelimb, contralateral to the investigated cortical zone, was monitored during locomotion. To accomplish this, a thin rubber sack was placed on the rabbit's forelimb, a thin metal electrode was attached to the external surface of the sack under the foot, and a voltage of 2-5 mV was applied to the electrode. The floor of the experimental box was covered by a cloth moistened with $0.1 \%$ sodium chloride to make the surface electrically conductive. A wire, sewn into the cloth along the length of the box, was connected to a common ground. The fall of voltage resulting from contact of the foot with the floor was recorded. The start 
and finish of electrical contact was taken as the start and finish of the stance phase of a step.

Identification of neurons. All neurons were tested for antidromic activation using $0.2 \mathrm{msec}$ rectangular pulses of graded intensity in the range of 0.1-2 mA. The principal criterion for the identification of antidromic activation was the test for collision of spikes (Bishop et al., 1962; Fuller and Schlag, 1976). Silent neurons that could not be tested for collision were considered to be antidromically activated if they satisfied two ancillary criteria: (1) a refractory period of $<2.0 \mathrm{msec}$ and (2) latency variability to a test stimulus of either $<0.1 \mathrm{msec}$ or $<1 \%$ of the antidromic latency, whichever is greater when the test stimulus followed a suprathreshold conditioning stimulus at an interval of $10 \mathrm{msec}$ (Swadlow et al., 1978). SINs were defined according to previously developed criteria (Swadlow, 1988, 1989, 1990, 1991, 1994). These neurons did not respond antidromically but did respond synaptically to electrical stimulation of the ipsilateral ventrolateral thalamus, primary somatosensory cortex, or the other hemisphere with a burst of three or more spikes occurring at peak frequency of $>600 \mathrm{~Hz}$. The nonidentified neurons (NIs) in this study were the cells that (1) did not respond to electrical stimulation of the contralateral motor cortex and therefore most likely did not project to it (the size of the motor limb representation in the rabbit cortex is so small that we likely excited most axons in it), (2) did not respond to electrical stimulation of the ventrolateral thalamus and therefore most likely did not project to it for the same reason, and (3) did not respond synaptically with a SIN-like burst to stimulation of either hemisphere or ventrolateral thalamus. Thus, NIs probably included other interneurons and neurons that projected to other cortical and subcortical targets but for the most part not to the ventrolateral thalamus or contralateral motor cortex.

Differentiation of CF5 and CF6 neurons. In both sensory and motor cortex, layer VI is characterized by the presence of efferent neurons (CF6s) with slowly conducting axons that exhibit a marked "supernormal" period of reduced antidromic latency at $8-12$ msec intervals after a previous action potential (Swadlow, 1989, 1990, 1991, 1994). In contrast, layer $\mathrm{V}$ is characterized by descending corticofugal neurons (CF5s) with rapidly conducting axons that do not exhibit supernormality. Thus, when the microelectrode reached a certain depth, the characteristics of those neurons activated antidromically via stimulation of ventrolateral thalamus changed. The most superficial CF6 neuron in each penetration was identified by (1) an antidromic latency of $>3 \mathrm{msec}$ and (2) a supernormal antidromic decrease of $>4 \%$ to a thalamic stimulus that followed a previous impulse (spontaneous or electrically elicited) at an interval of 8-12 msec. All descending corticofugal neurons located at this depth or deeper were classified as CF6 neurons. The axons of CF6 neurons are of fine diameter and thus have high thresholds to electrical stimulation (Rank, 1975; Nowak and Bullier, 1996; for review, see Swadlow, 1998). Therefore, it is likely that we excited axons passing or terminating very near the stimulation site in ventrolateral thalamus. CF6 neurons may be considered to be corticothalamic, because anatomical studies show that descending efferent axons of cortical layer VI terminate exclusively in the thalamus (Jones, 1984). Descending corticofugal neurons located at least $50 \mu \mathrm{m}$ superficial to the first encountered CF6 neuron were classified as CF5 neurons. For CF5 identification, we used currents in the range of $100-500 \mu \mathrm{A}$ only. Such stimulation did not evoke any visible muscle contraction; thus it was not substantially exciting axons in the internal capsule that was $\geq 2 \mathrm{~mm}$ away from the site of stimulation. Nevertheless, CF5 neurons of this study probably represent a heterogeneous population of corticofugal neurons, because, in addition to activating axons that terminate within the thalamus, we could be activating (1) axons in passage through or near to the thalamus or (2) collaterals of axons terminating in the thalamus but projecting a main axon more distally. Neurons that were found $<50 \mu \mathrm{m}$ above the first CF6 neuron were not classified as being in an uncertain cortical layer.

Processing of locomotion-related neuronal activity. The onset of the swing phase was taken as the beginning of the step cycle. The duration of each step cycle was divided into 10 equal bins. The discharge frequency in a bin was derived according to the method of Udo et al. (1982). The frequency histograms were smoothed using moving filter with a span of three. The following parameters were calculated for each neuron: (1) The mean frequency of discharge. (2) The Rayleigh test for directionality was used to determine whether the activity of a neuron was modulated. If it was, the coefficient of modulation $(M)$ was calculated as follows: $M=$ $\left(1-F_{\min } / F_{\max }\right) \times 100 \%$, where $F_{\min }$ and $F_{\max }$ are the minimal and the maximal frequencies of discharge in the histogram. (3) The preferred step phase of the discharge of the neuron was assessed using circular statistics. The occurrence of each spike was presented as a vector of a unit length. The angle (the phase) of it was calculated by multiplying the relative position of the spike in the step cycle (in portions of the cycle) by $2 \pi$. The phase of the mean vector (the preferred phase) was calculated. (4) The change of the mean frequency, the coefficient of frequency modulation, and the preferred phase on transition from simple to complex locomotion were also calculated.

Gait analysis. In experiments without unit recording, an analysis of the kinematics of locomotion was performed using a video-recording technique. The movements of rabbits were videotaped from the side by a two-dimensional Peak Performance System at 60 frames/sec. Lightreflecting paper stickers were attached to the skin projections of the joints. The video camera was positioned $3 \mathrm{~m}$ from the side of the chamber.

Statistical procedures. Parametric tests were used when possible for comparisons between groups. For all mean values, the SEM is given. The discharge frequency and modulation of neurons during simple and complex locomotion was compared using the paired-samples $t$ test. The phase relationship between a locomotion task and the activity of neurons was determined and compared across the tasks using circular statistics (Batschelet, 1981; Fisher, 1993). When data were categorical, the nonparametric Mann-Whitney $U$ test was used.

Histological procedures. At the termination of the experiment, rabbits were deeply anesthetized with pentobarbital sodium and perfused with isotonic saline followed by a $10 \%$ formalin solution. Frozen brain sections of $50 \mu \mathrm{m}$ thickness were cut in the regions of recording and stimulating electrodes so that their locations could be verified by observation of electrode track gliosis. The tissue was stained for Nissl substance with cresyl violet.

\section{Results}

\section{Characteristics of simple and complex locomotion}

The gait that rabbits used both on the flat surface (simple locomotion) and during overstepping a series of barriers (complex locomotion) was a slow gallop (velocity of 1.2-1.4 m/sec; step duration of $350 \pm 20 \mathrm{msec}$; mean \pm SEM). Figure $3 A$ and $B$ illustrate the step phases during the two locomotion tasks. Each step included the following phases: (1) two hindlimbs support, (2) three limbs support, (3) two forelimb support, and (4) one forelimb support. To clear the barriers, rabbits lifted the limbs much higher compared with simple locomotion. This was achieved by an additional flexion in all of the joints during the swing phase (Fig. 3C,D). However, during both locomotion tasks, the durations of the swing and the stance phases were similar.

The variability of the step lengths during simple locomotion was considerable. Figure $3 E$ shows 20 simple locomotion passages that were aligned on the position of the toes in the first step. Because of the variability of the step lengths, the positions of the footprints generated by the two successive steps were progressively more variable. Figure $3 F$ presents 20 complex locomotion passages that were aligned on the position of the barriers (vertical bars) that restricted the permissible positions for the paws on the floor. In these tracks, the footprints before barriers 2 and 3 were made at very similar positions, despite the starting positions being considerably different. Thus, complex locomotion was characterized by a more precise positioning of feet on the surface compared with simple locomotion. 
A

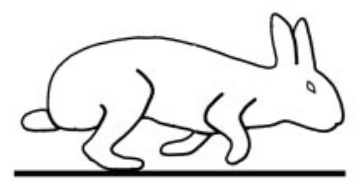

B

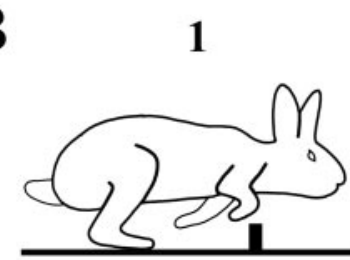

2

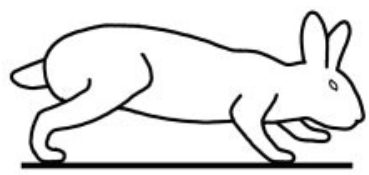

2

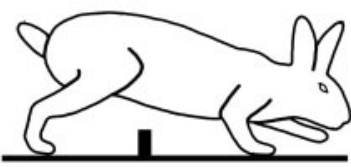

3

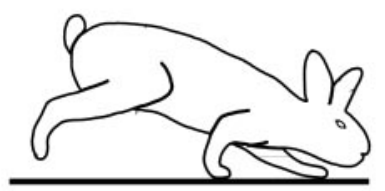

3

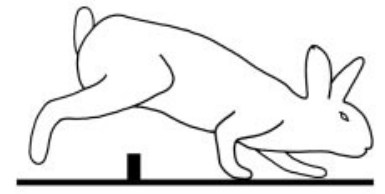

4

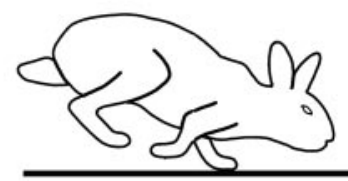

4

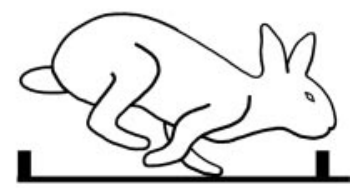

C

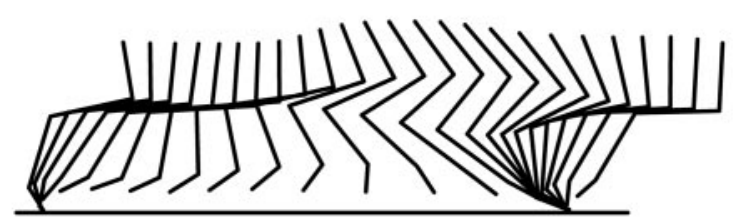

D

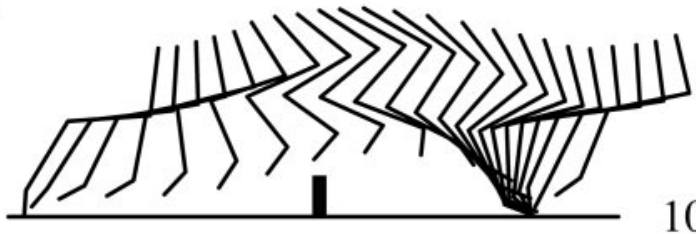

F

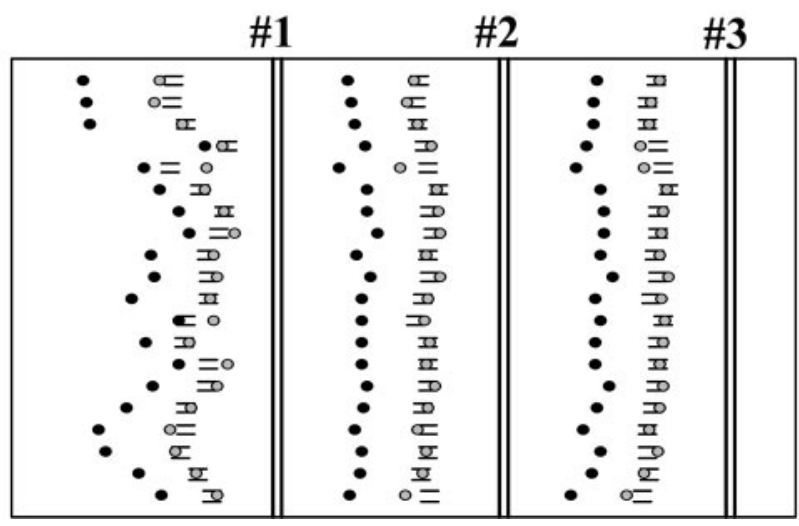

Figure 3. Characteristics of simple and complex locomotion. $A, B$, Body configuration in four sequential phases of the locomotor cycle (1-4) are shown for simple $(A)$ and complex ( $B)$ locomotion. $C, D$, Sequential positions of the "leading" forelimb presented as stick figures for one representative step for simple $(C)$ and complex $(D)$ locomotion. E, F, Footprints in 20 sequential passages during simple $(E)$ and complex $(F)$ locomotion. Three steps in each passage are shown. Black circles indicate footprints of the leading forelimb, gray circles indicate footprints of the trailing forelimb, and bars indicate footprints of the hindlimbs. The positions of barriers $1-3$ in $F$ are shown by vertical bars. The direction of progression in $C-F$ was from left to right.

\section{Activity of CF5 neurons}

Figure $4 \mathrm{~A}$ presents an example of activity of a CF5 neuron at rest, during simple locomotion, and during complex locomotion. At rest the neuron discharged with a frequency of $\sim 6 \mathrm{~Hz}$. During simple locomotion, the discharge of the neuron was modulated, discharging more during the swing phase than during the stance phase. During complex locomotion, the discharge of the neuron during the swing phase was even greater, but the activity during the stance phase was still low. The pattern of activity of the neuron was rather consistent, as illustrated in the rasters that show discharges of the neuron in 50 steps during simple (Fig. $4 \mathrm{~B}$ ) and complex (Fig. 4C) locomotion. Figure $4 D$ and $E$ presents discharge frequency of the neuron as a function of the step phase. During simple locomotion (Fig. 4D), the neuron had a sharper peak in the swing phase, whereas during complex locomotion (Fig. $4 E$ ), the peak was wider.

All 24 CF5 neurons studied were active at rest $[5.7 \pm 1.0$ impulses (imp)/sec] and during simple locomotion (7.3 \pm 1.3 $\mathrm{imp} / \mathrm{sec}$ ). During simple locomotion, the discharge of $88 \%$ of these neurons was modulated in the step cycle. The coefficient of frequency modulation $(M)$ was $71 \pm 4 \%$. The activity of different CF5s had different preferred phases in the step cycle; however, the preferred phase of $45 \%$ of CF5s was in the first half of the swing (Fig. $4 F$ ).

During complex locomotion, all CF5 neurons were also active $(8.8 \pm 1.3 \mathrm{imp} / \mathrm{sec})$. The discharge of $96 \%$ of these neurons was modulated in relation to the step cycle. The $M$ was $79 \pm 2 \%$. The mean activity and modulation values as well as the percentage of neurons involved in the locomotion task were not significantly different during complex locomotion compared with simple locomotion. As during simple locomotion, the activity of different CF5s had different preferred step phases during complex locomotion. However, in contrast to simple locomotion, distribution of the preferred phases of different neurons was rather equal across the step cycle (Fig. 4G). This change in the preferred phase of the CF5 population activity was attributable to shifts of pre- 


\section{A}

\section{$\underline{\text { Flat surface }}$}
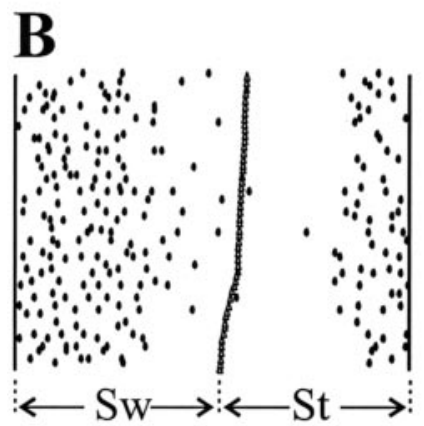

C

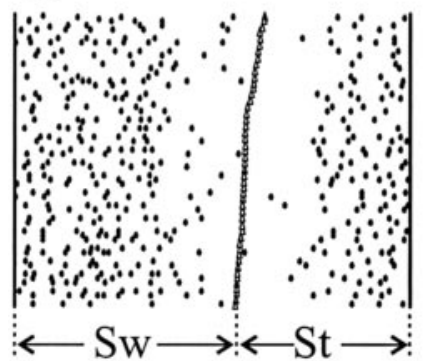

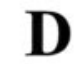

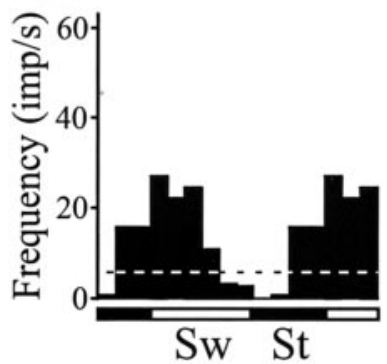

Barriers

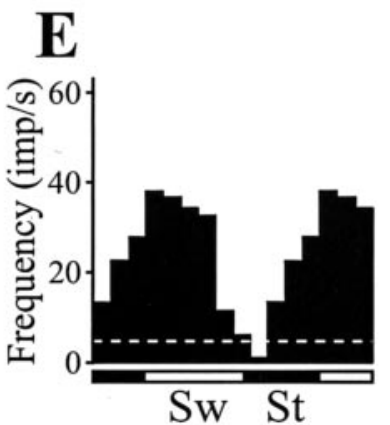

Changes of activity

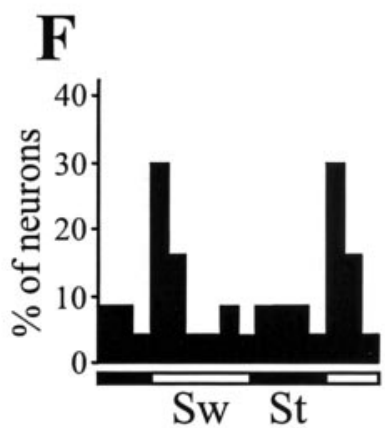

H
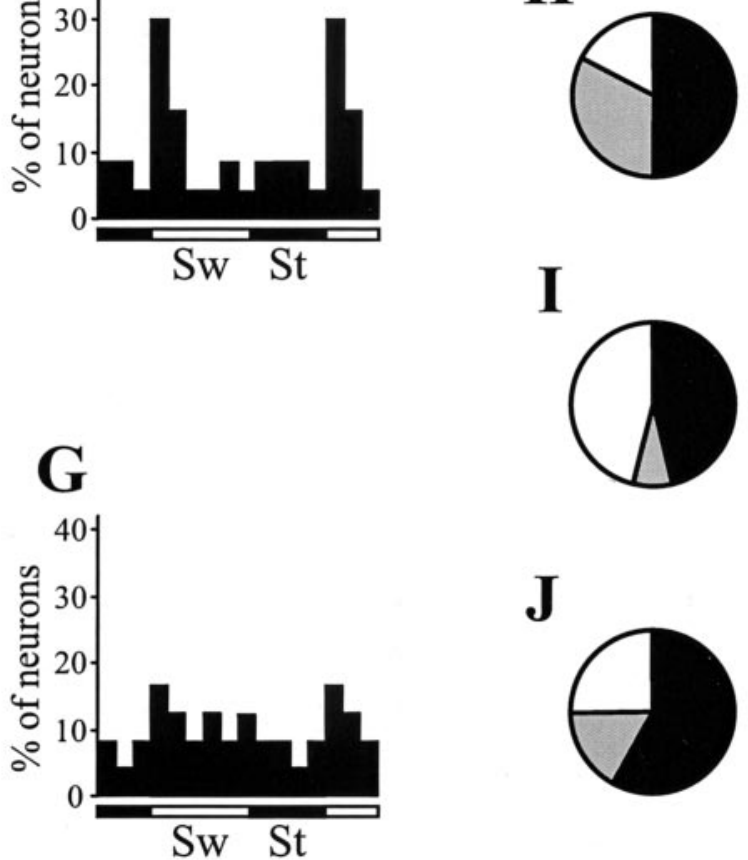

Figure 4. Activity of CF5 neurons during locomotion. $A$, A representative record of a CF5 neuron discharge at rest and during simple and complex locomotion. The bottom trace shows the swing (SW) and stance (St) phases of the step cycle of the forelimb contralateral to the recording site in the cortex. B, D, Activity of the same CF5 neuron during simple locomotion is presented as a raster of 50 step cycles $(B)$ and as a histogram $(D)$. In the raster, the duration of step cycles is normalized to $100 \%$, and the raster is rank-ordered according to the duration of the swing phase. The beginning of the stance phase in each step is indicated by an open triangle. In the histogram, the dashed line shows the level of activity at rest. $C, E$, Activity of the same neuron during complex locomotion presented as a raster $(C)$ and as a histogram $(E) . F, G$, Distribution of preferred phases (positions of mean vectors) of activity of all (F5 neurons in the normalized step cycle during simple $(F)$ and complex ( $G$ ) locomotion. $H, I$, Proportion of neurons in which the mean discharge frequency increased (black), decreased ( gray), and did not change (white) on transition from rest to locomotion ( $H$ ) and from simple to complex locomotion $(/)$.J, Proportion of neurons in which the coefficient of frequency modulation increased, decreased, and did not change on transition from simple to complex locomotion; color codes are same as in $\mathrm{H}$ and $I$.

ferred phases in $25 \%$ of individual neurons by $1 / 10$ and to shifts in $17 \%$ of them by one-fifth to one-half of the duration of the cycle, while the preferred phases of $58 \%$ of the neurons stayed unchanged on transition from simple to complex locomotion.

Although the mean activity and modulation values for the CF5 population were close during simple and complex locomotion, individual CF5 neurons expressed significant changes in both of these parameters on transition from simple to complex locomotion, as demonstrated by the paired-samples $t$ test $(p<$ 0.03 or better). This transition was associated with an increase in the mean frequency in $46 \%$ of CF5s and with a decrease in $8 \%$ of them (Fig. $4 I$ ). The $M$ increased in $58 \%$ and decreased in $17 \%$ of the neurons (Fig. $4 J$ ). There was also a change in the mean frequency of most CF5s on transition from rest to simple locomo- tion ( $p<0.005$; paired $t$ test): it increased in one-half of the neurons and decreased in 33\% of them (Fig. $4 H$ ).

\section{Activity of CF6 neurons}

The CF6 neurons were very distinct from CF5 neurons. At rest, $66 \%$ (16 of 24) of these neurons were virtually silent, emitting $<1 \mathrm{imp} /$ min during a 10 min test period. The mean rate for all CF6s was $0.4 \pm 0.1 \mathrm{imp} / \mathrm{sec}$, and that for the active cells only was $1.1 \pm 0.3$ $\mathrm{imp} / \mathrm{sec}$, which was significantly lower than that of CF5 neurons, all of which were active at rest $(p<0.001 ; U$ test) (see Fig. $8 A$ ).

During simple locomotion, only 25\% (6 of 24) of CF6s showed some level of activity. However the discharge rates of these CF6 neurons were significantly lower than those of CF5s that were tested under the same conditions $(2.3 \pm 1.1 \mathrm{imp} / \mathrm{sec}$ vs 
$7.3 \pm 1.3 \mathrm{imp} / \mathrm{sec} ; p<0.02 ; U$ test) (see Fig. $8 B$ ). Five CF6 neurons that were active at rest were silent for the period of locomotion (Fig. 5A). Of six cells active during locomotion, the step-related modulation was pronounced in the activity of four of these cells ( $17 \%$ of the total population) (see Fig. $8 D$ ). The $M$ was in the range of $65-100 \%$. The activity of different CF6 neurons had different preferred step phases.

There was little change in the activity of CF6 neurons on transition from simple to complex locomotion. The six neurons that were active during simple locomotion were also active during complex locomotion, with discharge rates lower than those in the corresponding CF5 group ( $4.4 \pm 2.4 \mathrm{imp} / \mathrm{sec}$ vs $8.8 \pm 1.3 \mathrm{imp} / \mathrm{sec}$ for the CF5s; $p<0.03$; $U$ test) (see Fig. $8 C$ ). Of the four CF6 neurons whose activity was modulated during simple locomotion, only one showed a change in this modulation during complex locomotion. Figure $5 B-E$ illustrates the activity of that one neuron in 50 steps during each simple and complex locomotion. The discharge frequency of the neuron during simple locomotion was extremely low, but the activity did show a step-related modulation (six of seven action potentials occurred during stance phase). The discharge frequency of the neuron during complex locomotion was still low, and the step-related modulation was weaker.

The CF6 neurons that were active during locomotion did not have any other properties that would distinguish them from the silent CF6s. These cells had a wide variety of conduction velocities and supernormal conductivity. They had no obvious receptive fields and did not respond synaptically to electrical stimulation of any of the sites tested.

\section{Activity of CCC and CCI neurons}

The two types of CC neurons, CCIs and CCCs, behaved similarly and will be considered together. CC neurons, like the CF6 population described above, were very different from the CF5 group, in that many CC neurons were weakly if at all active at rest and during locomotion.

At rest, 49\% (19 of 39) of CC neurons were virtually silent, emitting $<1 \mathrm{imp} / \mathrm{min}$ during a $10 \mathrm{~min}$ test period. The mean rate for all CCs was $0.6 \pm 0.1 \mathrm{imp} / \mathrm{sec}$, and that for the active cells only was $1.2 \pm 0.2 \mathrm{imp} / \mathrm{sec}$, which was significantly lower that that of CF5s ( $p<0.001 ; U$ test) (see Fig. $8 A$ ). During simple locomotion, $56 \%$ of CC neurons were active. However the rates of activity of these neurons were still very low when compared with CF5 neurons under the same testing conditions $(2.4 \pm 0.9 \mathrm{imp} / \mathrm{sec}$ vs $7.3 \pm 1.3 \mathrm{imp} / \mathrm{sec} ; p<0.001 ; U$ test) (see Fig. $8 B$ ). The activity of $28 \%$ of CC neurons was modulated in relation to locomotion cycle (see Fig. $8 D$ ), with the $M$ in the range of $85-100 \%$. The preferred step phases of activity of different CC neurons were distributed over step cycle.

During complex locomotion, 54\% of the CC neurons were active. Those were the same neurons that were also active during simple locomotion. During complex locomotion, the discharge rates of CCs were still lower than those of CF5s $(4.0 \pm 1.4 \mathrm{imp} / \mathrm{sec}$ vs $8.8 \pm 1.3 \mathrm{imp} / \mathrm{sec} ; p<0.002 ; U$ test) (see Fig. $8 B$ ). The activity was modulated in $33 \%$ of the CCs (see Fig. $8 E$ ), with the $M$ in the range of $67-100 \%$. These values were derived from the same neurons that were modulated during simple locomotion plus two neurons that were only modulated during complex locomotion. They were similar to the values obtained during simple locomotion. The activity of different CCs had different preferred step phases. Figure $6 A-D$ illustrates the activity of one of the active and modulated CC neurons in 50 steps during simple and complex locomotion. The low discharge of this neuron peaked at the

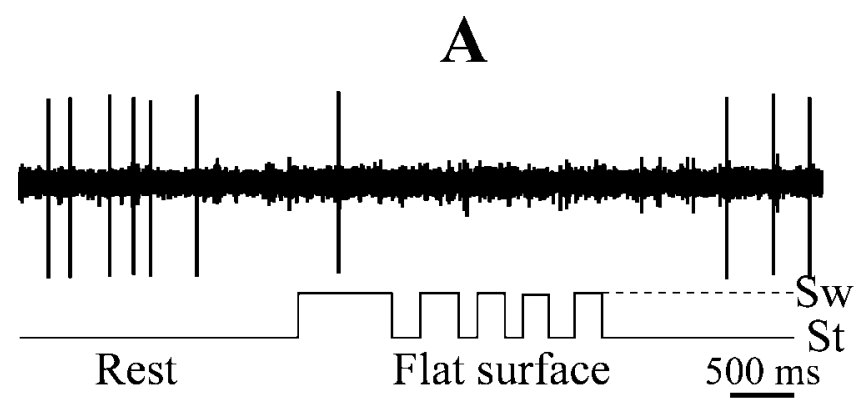

\section{Flat surface}

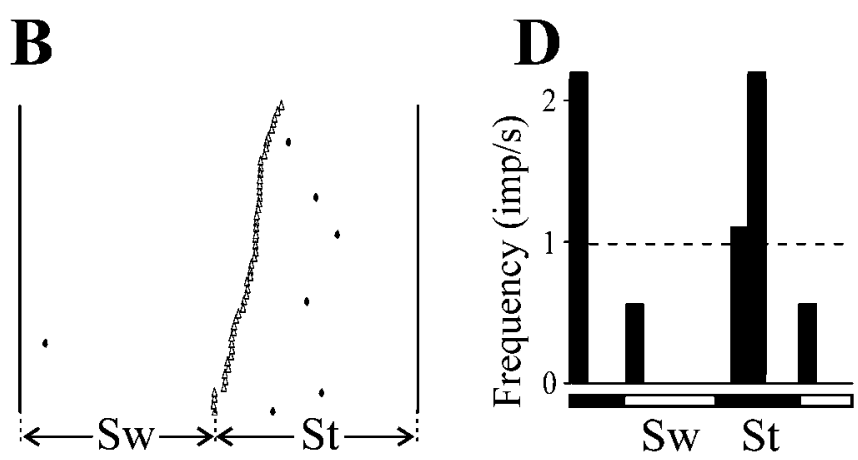

\section{Barriers}
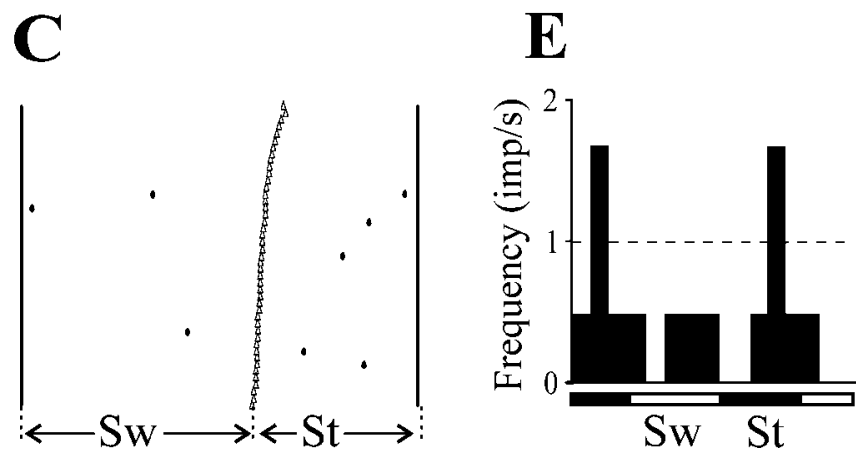

Figure 5. Examples of activity of CF6 neurons during locomotion. $A$, Inhibition of the discharge of a neuron during locomotion. $B-E, A$ raster and a histogram for simple $(B, D)$ and complex $(C, E)$ locomotion for a typical CF6 neuron are shown. Designations are as in Figure 4.

end of swing during both simple and complex locomotion, but the peak was wider during complex locomotion.

Although the mean activity values for the CC population were close during simple and complex locomotion, the frequency of many individual CC neurons changed on transition from simple to complex locomotion, as demonstrated by the paired-samples $t$ test ( $p<0.02$ or better). This transition was associated with an increase in the mean frequency in $38 \%$ of CCs and with a decrease in $6 \%$ of them (Fig. $6 F$ ). However, the $M$ increased in $11 \%$ and decreased in $11 \%$ of the neurons only (Fig. $6 G$ ). The mean frequency of $56 \%$ of the neurons increased ( $p<0.001$; paired $t$ test), and that of $38 \%$ of the neurons decreased ( $p<0.02$; paired $t$ test) also on transition from rest to simple locomotion (Fig. 6E).

The CC neurons that were active during locomotion had significantly higher conduction velocities than did the silent CCs $(1.2 \mathrm{~m} / \mathrm{sec}$ compared with $0.6 \mathrm{~m} / \mathrm{sec} ; p<0.015$; $U$ test $)$, and among them there were more cells with somatosensory receptive 


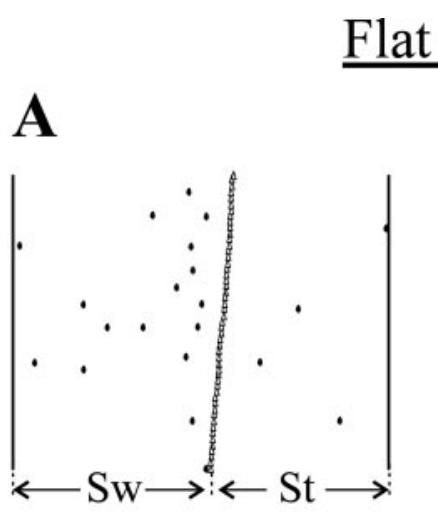

Flat surface
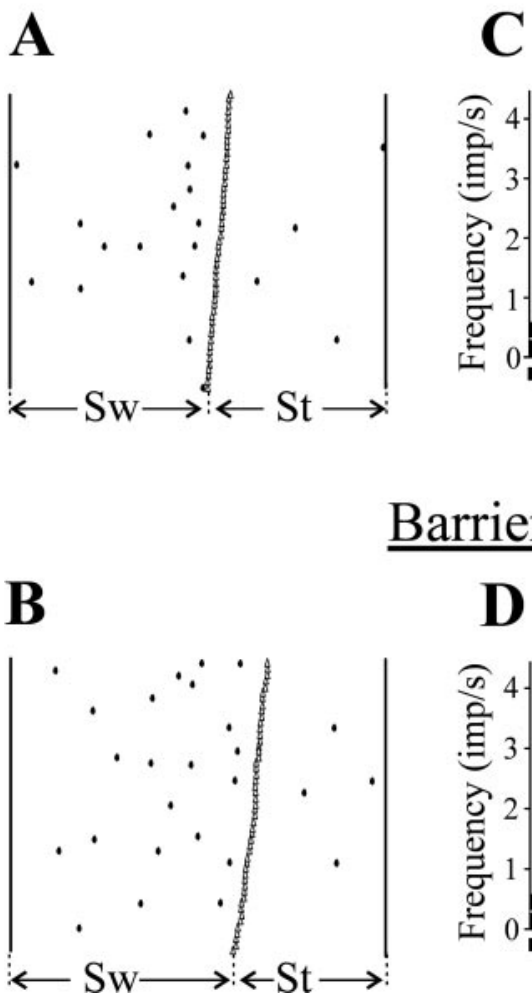

\section{$\underline{\text { Barriers }}$}
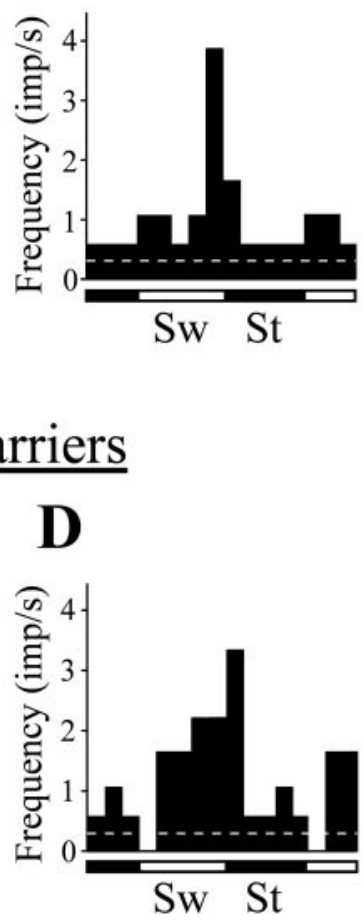

Figure 6. Activity of $C C$ neurons during locomotion. $A-D$, Examples of activity of one of the most active and modulated CC neurons during locomotion. A raster and a histogram are shown for simple $(A, C)$ and complex $(B, D)$ locomotion. $E, F$, Proportion of neurons in which the discharge rate increased (black), decreased ( gray), and did not change (white) on transition from rest to locomotion $(E)$ and from simple to complex locomotion $(F)$. $G$, Proportion of neurons in which the coefficient of frequency modulation increased, decreased, and did not change on transition from simple to complex locomotion. Designations are as in Figure 4.

fields. However, the active CCs did not have any distinct laminar distribution.

\section{Activity of SINs}

Figure 7 presents an example of activity of a SIN at rest and during locomotion. At rest the neuron discharged with a frequency of $\sim 14 \mathrm{~Hz}$. During simple locomotion the frequency of the discharge was considerably higher. In addition, the discharge of the neuron was modulated in locomotion cycle with a peak in the late swing-early stance phase. The pattern of activity of the neuron was rather consistent, as illustrated in the raster that shows discharge of the neuron in 50 steps during simple (Fig. 7B) and complex (Fig. 7C) locomotion. During complex locomotion, the discharge frequency in the late stance-early swing was much lower compared with that during simple locomotion (was below the rest level), while it was still high in the late swing-early stance phase (Fig. 7D,E).

All 46 SINs studied were active at rest $(16.8 \pm 1.7 \mathrm{imp} / \mathrm{sec})$ (Fig. $8 A$ ). During simple locomotion, all SINs were also active; however, the mean frequency was twice as high compared to rest $(33.9 \pm 3.2 \mathrm{imp} / \mathrm{sec}$ ) (Fig. 8 B). The discharge of $65 \%$ of SINs was modulated in the step cycle (Fig. $8 D$ ). The $M$ of SINs was $65 \pm$ $2 \%$ (Fig. $8 F$ ). Different SINs had different preferred step phases; however, the preferred phase of $50 \%$ of them was in the first half of the stance (Fig. $7 F$ ) [i.e., in the anti-phase with the preferred phase of CF5 neurons (Fig. $4 F$ )].

During complex locomotion, all SINs were active as well
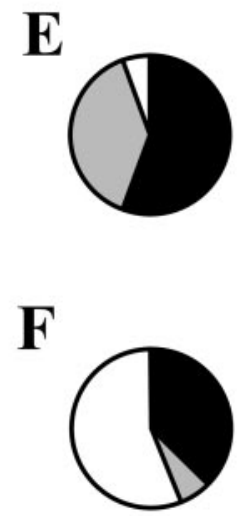

\section{Changes of activity}

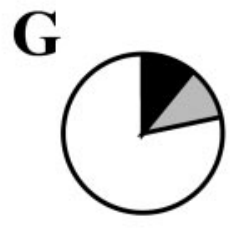
during simple and complex locomotion, individual neurons did demonstrate significant changes in both of these parameters on transition from simple to complex locomotion (by paired-samples $t$ test; $p<0.04$ or better). This transition was associated with an increase in the mean frequency in $22 \%$ of SINs and with a decrease in $17 \%$ of them (Fig. $7 I$ ). The $M$ increased in 35\% and decreased in $20 \%$ of the neurons (Fig. $7 J$ ). There was also a change in the mean discharge frequency on transition from rest to simple locomotion ( $p<0.001$; paired $t$ test) in the overwhelming majority of SINs: it increased in $83 \%$ and decreased in $9 \%$ of the neurons (Fig. $7 \mathrm{H}$ ).

During both simple and complex locomotion, the $M$ values of SINs that responded with latencies of $<2.5 \mathrm{msec}$ to stimulation of the ventrolateral thalamus were higher than those of the cells that responded with longer latencies ( $p<0.04 ; U$ test). There was no correlation between the strength of locomotion-related modulation and the latency with which SINs responded to stimulation of any cortical sites. Although not statistically significant, there was a trend for the activity of SINs found in cortical layers II and III to be more often linked to stepping movements than was the activity of SINs found in layers V and VI.

\section{Activity of NI neurons}

All 62 NI neurons studied were active at rest $(6.3 \pm 0.7 \mathrm{imp} / \mathrm{sec})$. During simple locomotion, all NI neurons were also active ( $8.5 \pm$ $1.0 \mathrm{imp} / \mathrm{sec}$ ) (Fig. $8 A, B)$. The discharge of $80 \%$ of the neurons was modulated in the locomotion rhythm (Fig. $8 D$ ). The mean $M$ was $65 \pm 3 \%$ (Fig. $8 F$ ). Different NI neurons had different preferred step phases, with slightly more cells having them in the swing phase.

During complex locomotion, all NI neurons were active as well $(8.8 \pm 1.2 \mathrm{imp} / \mathrm{sec}$ ) (Fig. $8 C)$. The discharge of $90 \%$ of the neurons was modulated (Fig. $8 E$ ). The $M$ was $67 \pm 2 \%$ (Fig. $8 G$ ). The mean activity and modulation values as well as the percent- 


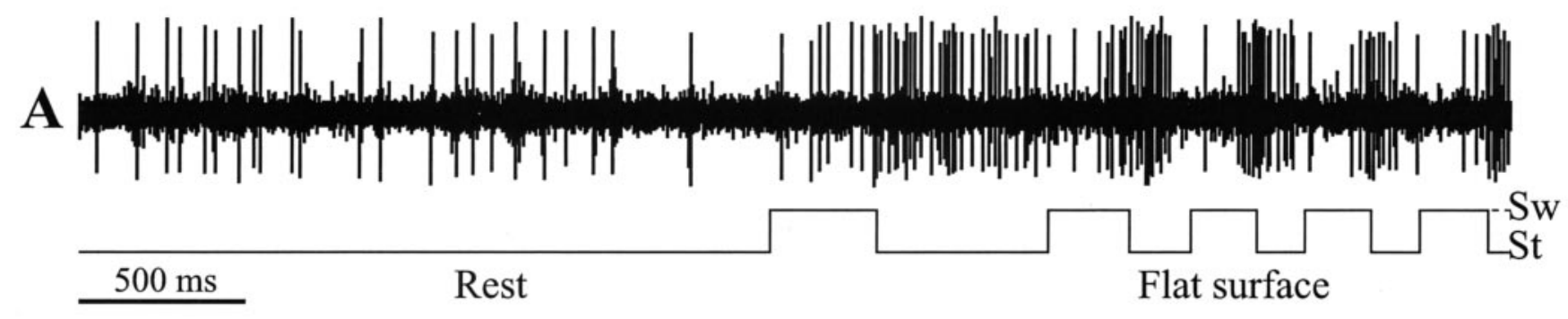

$\underline{\text { Flat surface }}$
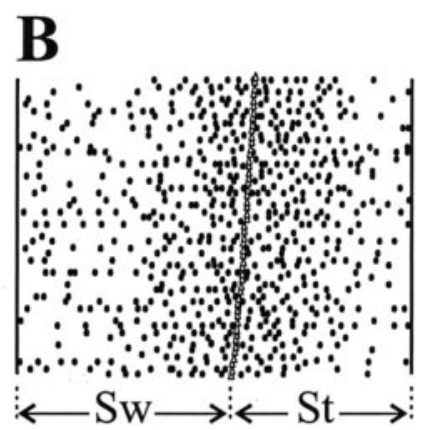

C

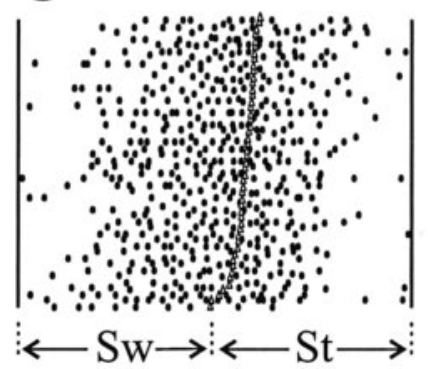

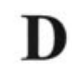

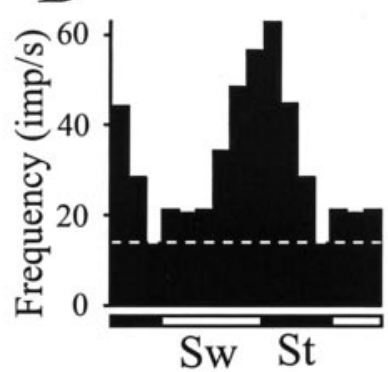

$\underline{\text { Barriers }}$

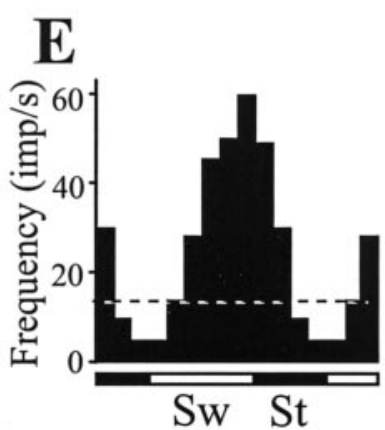

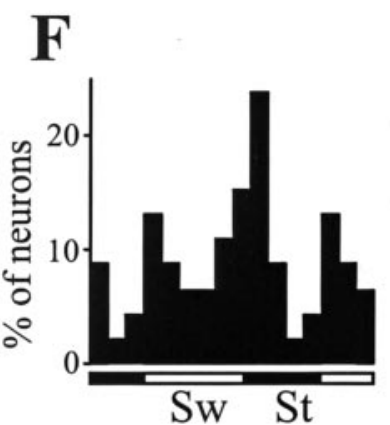

$\frac{\text { Changes }}{\text { of activity }}$

H

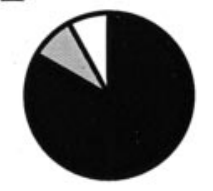

I
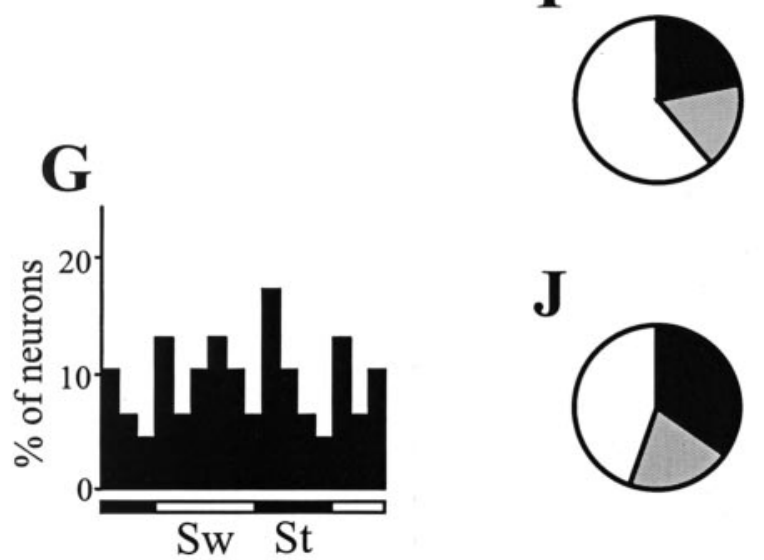

Figure 7. Activity of SINs during locomotion. $A$, A representative record of a SIN discharge at rest and during simple locomotion. $B, D$, Activity of the same SIN during simple locomotion is presented as a raster of 50 normalized step cycles $(B)$ and as a histogram $(D) . C, E$, Activity of the same neuron during complex locomotion is presented as a raster $(C)$ and as a histogram $(E)$. $F, G$, Distribution of preferred phases (positions of mean vectors) of activity of all SINs in the normalized step cycle during simple $(F)$, and complex ( $G$ ) Iocomotion. $H$, I, Proportion of neurons in which the discharge frequency increased (black), decreased ( gray), and did not change (white) on transition from rest to locomotion $(H)$ and from simple to complex locomotion ( $I$ ). J, Proportion of neurons in which the coefficient of frequency modulation increased, decreased, and did not change on transition from simple to complex locomotion. Designations are as in Figure 4.

age of neurons involved in locomotion task and their preferred phase distribution were not significantly different during complex versus simple locomotion. However, individual NI neurons demonstrated significant changes in their discharge frequency and modulation on transition from simple to complex locomotion, as demonstrated by the paired-samples $t$ test $(p<0.02$ or better). The mean frequency increased in 33\% of NIs and decreased in $34 \%$ of them. The $M$ increased in $48 \%$ and decreased in $21 \%$ of the neurons.

\section{Discussion}

Activity of different types of efferent cortical neurons

Locomotion is one of the most complex motor behaviors. The entire skeletal musculature is involved in a highly coordinated activity. All motor centers (spinal cord, brain stem, cerebellum, motor cortex) participate in the generation of the locomotor pattern (Orlovsky at al., 1999). In addition, locomotion in natural environments, over uneven surfaces, requires visuomotor coordination for successful avoidance of obstacles and precise feet positioning (Drew, 1991; Patla et al., 1991; Hollands and Marple-Horvat, 1996). It has been shown that locomotion on uneven surfaces is not possible without the motor cortex (Trendelenberg, 1911; Liddell and Phillips, 1944; Beloozerova and Sirota, 1993), and recordings of motor cortical neurons during natural locomotion revealed significant differences in step-related activity when negotiating a complex versus a simple terrain (Beloozerova and Sirota, 1993; Drew, 1993; Widajewicz et al., 1994; Kably and Drew, 1998). These activity changes, which were associated with gait adjustments during locomotion on uneven surfaces, were interpreted as signals that were influencing other motor centers and responsible for the gait modifications.

Communication between motor centers is believed to be essential for normal motor behavior, especially for a complex motor behavior such as locomotion. However, only recently has the 


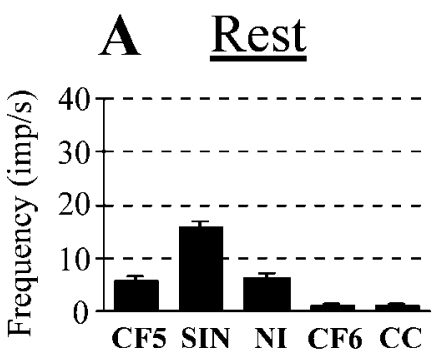

Flat surface
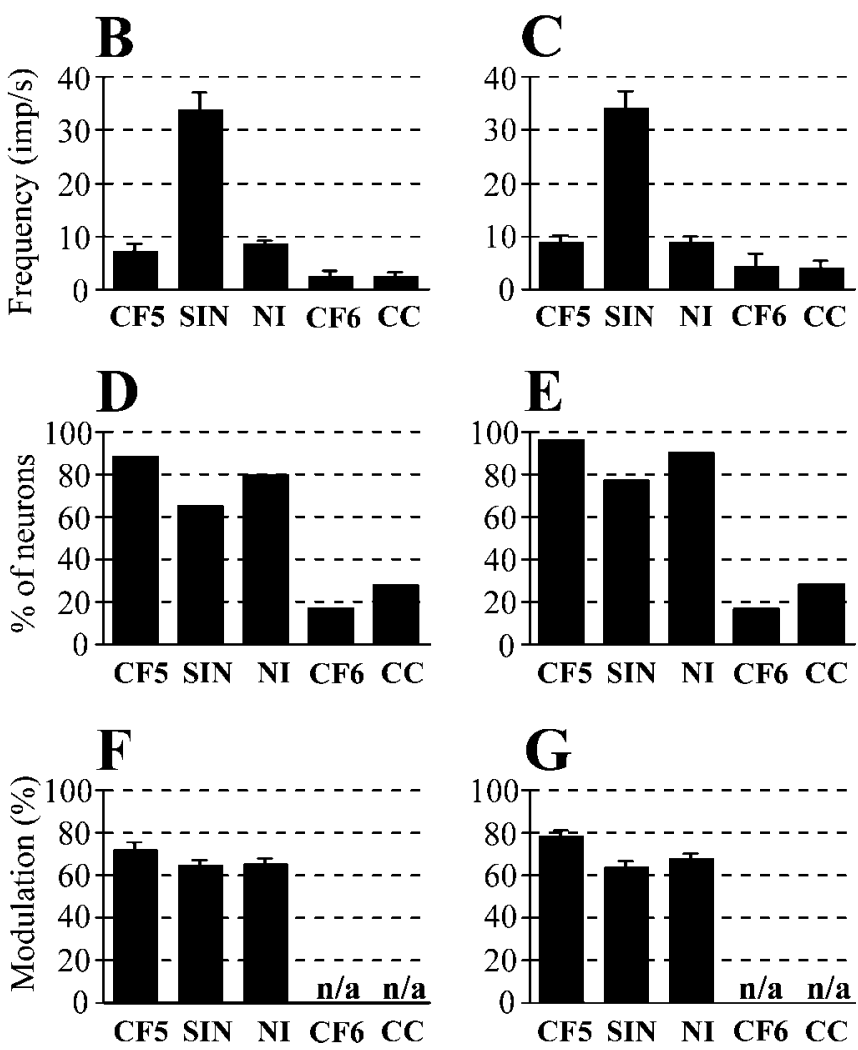

Figure 8. Characteristics of different neuronal groups. $A-C$, Mean discharge frequency of neurons of different groups at rest $(A)$, during simple locomotion $(B)$, and during complex locomotion ( $C$ ). For the $\mathrm{CF} 6$ and $\mathrm{C} C$ populations, the mean rates are presented across the active cells only. $D, E$, Percentage of neurons in which the activity was modulated in relation to the step cycle during simple $(D)$ and complex $(E)$ locomotion. $F, G$, Mean coefficient of modulation of neurons during simple $(F)$ and complex $(G)$ locomotion. Note that the differences in all of the parameters between different neuronal subpopulations were similar during simple and complex locomotion.

activity of the "communication lines" leading from the motor cortex, other than the corticospinal tract, been assessed during motor behaviors. In the walking cat, the activity of corticoreticular neurons in steps over an obstacle was considerably different from that during ordinary steps (Kably and Drew, 1998). In the monkey, the activity of corticorubral and corticostriatal neurons was correlated with forelimb movements (From, 1983; Bauswein et al., 1989; Turner and DeLong, 2000). However, both in the cat and in the monkey, the pattern of activity of the efferent neurons projecting to these subcortical targets was distinct from that of corticospinal neurons.

Based on the available data, we expected all efferent populations of the motor cortex to be active during locomotion and to have pronounced step-related discharges. This hypothesis was not confirmed, however. We found that the activity of several classes of motor cortical efferent neurons was only weakly related to the locomotion rhythm, (i.e., CCIs, CCCs, and CF6s). Most of these neurons were either silent or exhibited a weak step-related activity. The only cortical output that had a strong step-related activity was the CF5s.

Studies of motor and sensory cortices usually report very few cells that cannot be driven by movements of the animal or by peripheral stimulation. This is probably because the identification of a neuron is usually achieved by detecting its spontaneous activity or peripherally driven response. However, if a special effort is given to elicit a discharge of a neuron by an application of a neurotransmitter (Dykes and Lamour, 1988; Metherate et al., 1988) or by antidromic activation (Swadlow, 1988, 1989, 1990, 1991, 1994), a large number of silent and weakly active neurons may be identified. In many studies, lack of significant spontaneous or elicited activity has been attributed to anesthesia, pathology, or to a restraint and low activity of the animal. The present study was performed in awake and active animals. Moreover, the activity of the neurons was tested not only during simple locomotion on a flat surface, a predominantly spinally controlled behavior, but also during overstepping a series of barriers, a locomotion task that requires visuomotor coordination and cannot be accomplished without the motor cortex. However, the majority of CC and CF6 neurons still exhibited a low activity if any at all during both simple and complex locomotion. The activity and modulation of most neurons in these populations did not change on transition from simple to complex locomotion. In contrast, most CF5s, SINs, and NI neurons did change their activity and modulation during this transition. The activity of some CF6s was even inhibited for the period of locomotion. These findings are not specific for the rabbit. Similar results (i.e., the extremely low activity of CC and CF6 neurons during both simple and complex locomotion) have been obtained recently in the cat (I. N. Beloozerova and M. G. Sirota, unpublished observations). A low activity and a weak relationship of this activity to a reaching task in monkeys was reported recently for CF6 neurons that project from motor cortex to the pallidum-receiving portion of the motor thalamus (Ruffo et al., 2001).

The inactivity of many CCCs during locomotion suggests that coordination between the two symmetrical limbs during simple as well as the complex locomotion does not require interaction of the two hemispheres and is achieved at the brainstem-spinal level.

To explain a low activity of CCI neurons projecting to the ipsilateral somatosensory cortex, one should take into account that the main afferent input to the motor cortex during locomotion is from the ventrolateral thalamus (Beloozerova and Sirota, $1988,1998)$. Somatosensory signals do not play a significant role in modulation of the activity of the motor cortex during locomotion (Armstrong and Drew, 1984b). Therefore, it is reasonable that the somatosensory cortex also does not receive a potent feedback control from the motor cortex during locomotion.

The absence of activity in CF6 neurons during locomotion is most surprising. These neurons are usually considered to be an essential part of the thalamocortical loop (Sherman and Guillery, 2001). Our finding suggests that, at least during locomotion, functioning of this loop is primarily based on the feedback signals that are transmitted to the thalamus by CF5 neurons.

Thus, on the base of our observations as well as data that is available in literature (From, 1983; Bauswein et al., 1989; Kably and Drew, 1998; Turner and DeLong, 2000; Ruffo et al., 2001), one can draw two conclusions: (1) The signals that are transmit- 
ted from the motor cortex to its diverse targets via different communication lines are substantially different. (2) The efferent neurons that are located in layer $\mathrm{V}$ of the motor cortex are most intensively involved in control of movements.

\section{Formation of corticofugal signals}

The motor cortex receives input signals related to locomotion primarily from the ventrolateral thalamus, and in the absence of this input, the locomotion-related modulation of cortical activity nearly vanishes (Beloozerova and Sirota, 1988, 1998). Projection neurons from ventrolateral thalamus synapse both on CF5 neurons and on inhibitory interneurons (Strick and Sterling, 1974), and inhibitory interneurons in turn synapse on CF5s (Strick and Sterling, 1974; White, 1989). In primary somatosensory cortex however, there is a dramatic difference in the efficacy of the ventrolateral projection onto SINs and onto CF5s: it is extremely potent in driving the SINs but not the CF5 neurons (Swadlow, 1995, 2000). In the present study performed in the motor cortex, we also did not see any potent synaptic responses to electrical stimulation of ventrolateral thalamus in CF5s found next to SINs, which were vigorously responding to such stimulation (Beloozerova, Sirota, and H. A. Swadlow, unpublished observations). During locomotion, the activity of ventrolateral thalamic projection neurons is modulated by the rhythm of stepping movements (Beloozerova and Sirota, 2002). We hypothesize that the activity of SINs increases at the onset of locomotion much more than that of CF5s, because the efficacy of input from the ventrolateral thalamus onto these cells is greater than that onto CF5s. During locomotion, SINs exhibited a clear-cut step-related modulation of their discharge. That modulation was stronger in SINs that received the fast input from ventrolateral thalamus than in SINs receiving the slow input. During simple locomotion, the peak of activity was pronounced in both SIN and CF5 populations, with the peaks being located in the opposite phases of the step cycle (Figs. $4 F, 7 F$ ). In contrast, during complex locomotion, the distribution of activity was nearly flat in both populations (Figs. $4 G$, $7 G$ ). These findings suggest that the periods of lower activity of CF5s are caused, at least partly, by inhibition performed by SINs. To clarify a contribution of the excitatory input from the ventrolateral thalamus, recording of the activity of thalamocortical neurons is necessary. This study is now in progress.

Inhibitory interneurons are thought to be involved in regulating both spatial and temporal response properties of sensory cortical neurons (Sillito, 1975; Hicks and Dykes, 1983; Dykes et al., 1984). In the prefrontal cortex of monkeys, it has been shown that putative interneurons and pyramidal tract neurons are active in anti-phase during the response phase of a working memory task (Wilson et al., 1994; Rao et al., 1999, 2000). Our observations, along with the results of inactivation studies (Matsumura et al., 1992; Li et al., 1993), suggest that cortical inhibitory interneurons play a role not only in shaping the response properties but also in shaping the action-related properties of efferent neurons.

Two locomotion tasks in this study, the simple and the complex, were associated with pronounced differences in the activity of individual CF5 and SIN neurons. Many CF5s and SINs increased both their mean frequency and the coefficient of modulation, but in some of these neurons these values decreased or did not change (Figs. $4 I, J, 7 I, J$ ). Because of the opposite changes in the activity of individual neurons, a transition from simple to complex locomotion caused only minor changes in the mean population characteristics (Fig. 8). A similar result was obtained in cats when comparing activities of cortical neurons during simple and complex locomotion (Beloozerova and Sirota, 1993).
One can therefore suggest that the differences in the simple versus the complex locomotor pattern (i.e., the additional lifting of the limbs and the high precision of the feet placing during complex locomotion) (Fig. 3) are caused not by a massive change in the activity of the entire population of cortical neurons but rather by significant modifications in the activity of individual neurons. It is important to stress that during the transition from simple to complex locomotion, the preferred step phase changed by $>1 /$ 10 th of the step cycle in $<20 \%$ of the neurons studied. As we have argued previously (Beloozerova and Sirota, 1993), stability of the phases of activity of individual neurons in the step cycle is an important feature of the cortical activity during locomotion. This stability guarantees that any influences from cortical neurons onto their targets will occur in the phases that are preset for each neuron and therefore will not interfere with the basic locomotion rhythm.

\section{References}

Armstrong DM, Drew T (1984a) Discharge of pyramidal tract and other motor cortical neurons during locomotion in the cat. J Physiol (Lond) 346:471-496.

Armstrong DM, Drew T (1984b) Locomotor-related neuronal discharges in cat motor cortex compared with peripheral receptive fields and evoked movements. J Physiol (Lond) 346:497-517.

Baker SN, Kilner JM, Pinches EM, Lemon RN (1999) The role of synchrony and oscillations in the motor output. Exp Brain Res 1999 128:109-117.

Batschelet E (1981) Circular statistic in biology. New York: Academic.

Bauswein E, Fromm C, Preuss A (1989) Corticostriatal cells in comparison with pyramidal tract neurons: contrasting properties in the behaving monkey. Brain Res 493:198-203.

Beloozerova IN, Sirota MG (1988) Role of motor cortex in control of locomotion. In: Stance and motion. Facts and concepts. (Gurfinkel VS, Ioffe ME, Massion J, Roll JP, eds), pp 163-176. New York: Plenum.

Beloozerova IN, Sirota MG (1993) The role of the motor cortex in the control of accuracy of locomotor movements in the cat. J Physiol (Lond) 461:1-25.

Beloozerova IN, Sirota MG (1998) Cortically controlled gait modifications in the cat. Ann NY Acad Sci 860:550-554.

Beloozerova IN, Sirota MG (2002) Activity of ventrolateral thalamus (VL) during locomotion. Soc Neurosci Abstr 28:62.13.

Beloozerova IN, Sirota MG, Swadlow HA (1998) Putative inhibitory interneurons in the motor cortex: activity during locomotion. Soc Neurosci Abstr 24:158.18.

Beloozerova IN, Sirota MG, Swadlow HA (1999) Efferent neurons in the motor cortex: activity and silence during locomotion. Soc Neurosci Abstr 25:665.20.

Bishop PO, Burke W, Davis R (1962) The identification of single units in central visual pathways. J Physiol (Lond) 162:409-431.

Drew T (1991) Visuomotor coordination in locomotion. Curr Opin Neurobiol 1:652-657.

Drew T (1993) Motor cortical activity during voluntary gait modifications in the cat. I. Cells related to the forelimbs. J Neurophysiol 70:179-199.

Dykes RW, Lamour Y (1988) Neurons without demonstrable receptive fields outnumber neurons having receptive fields in samples from the somatosensory cortex of anesthetized or paralyzed cats and rats. Brain Res 440:133-143.

Dykes RW, Landry P, Metherate R, Hicks TP (1984) Functional role of GABA in cat primary somatosensory cortex: shaping receptive fields of cortical neurons. J Neurophysiol 52:1066-1093.

Evarts EV, Tanji J (1976) Reflex and intended responses in motor cortex pyramidal tract neurons of monkey. J Neurophysiol 39:1069-1080.

Evarts EV, Fromm C, Kroller J, Jennings A (1983) Motor cortex control of finely graded forces. J Neurophysiol 49:1199-1215.

Fisher NI (1993) Statistical analysis of circular data. Cambridge, UK: Cambridge UP.

Fromm C (1983) Contrasting properties of pyramidal tract neurons located in the precentral and postcentral areas and of corticorubral neurons in the behaving monkey. Adv Neurol 39:329-345.

Fuller JH, Schlag J (1976) Determination of antidromic excitation by the collision test: problems of interpretation. Brain Res 122:283-298. 
Gould HJ (1986) Body surface maps in the somatosensory cortex of rabbit. J Comp Neurol 243:207-233.

Hicks TP, Dykes RW (1983) Receptive field size for certain neurons in primary somatosensory cortex is determined by GABA-mediated intracortical inhibition. Brain Res 274:160-164.

Hollands MA, Marple-Horvat DE (1996) Visually guided stepping under conditions of step cycle-related denial of visual information. Exp Brain Res 109:343-356.

Jones EG (1984) Laminar distribution of cortical efferent cells. In: Cerebral cortex. Cellular components of the cerebral cortex, Vol 1 (Peters A, Jones EG, eds), pp 521-546. New York: Plenum.

Kably B, Drew T (1998) Corticoreticular pathways in the cat. II. Discharge activity of neurons in area 4 during voluntary gait modifications. J Neurophysiol 80:406-424.

Li BM, Matsumura M, Kubota K (1993) GABA $_{B}$ modulation of neuronal activity related to visually guided movement in the monkey premotor cortex. Neurosci Res 18:83-87.

Liddell EGT, Phillips CG (1944) Pyramidal section in the cat. Brain 67:1-9.

Matsumura M, Sawaguchi T, Kubota K (1992) GABAergic inhibition of neuronal activity in the primate motor and premotor cortex during voluntary movement. J Neurophysiol 68:692-702.

Matsunami K, Hamada I (1981) Characteristics of the ipsilateral movement-related neuron in the motor cortex of the monkey. Brain Res 204:29-42.

Metherate R, Tremblay N, Dykes RW (1988) The effect of acetylcholine on response properties of cat somatosensory cortical neurons. J Neurophysiol 59:1231-1252.

Nowak LG, Bullier J (1996) Spread of stimulating current in the cortical gray matter of rat visual cortex studied on a new in vitro slice preparation. J Neurosci Methods 67:237-248.

Orlovsky GN, Deliagina TG, Grillner S (1999) Neuronal control of locomotion. From mollusc to man. Oxford: Oxford UP.

Patla AE, Prentice SD, Robinson C, Neufeld J (1991) Visual control of locomotion: strategies for changing direction and for going over obstacles. J Exp Psychol Hum Percept Perform 17:603-634.

Porter R, Lewis M (1975) Relationship of neuronal discharges in the precentral gyrus of monkeys to the performance of arm movements. Brain Res 98:21-36.

Pryor K (1975) Lads before the wind. New York: Harper and Row.

Rank JB (1975) Which elements are excited in electrical stimulation of mammalian central nervous system: a review. Brain Res 98:417-440.

Rao SG, Williams GV, Goldman-Rakic PS (1999) Isodirectional tuning of adjacent interneurons and pyramidal cells during working memory: evidence for microcolumnar organization in PFC. J Neurophysiol 81:1903-1916.

Rao SG, Williams GV, Goldman-Rakic PS (2000) Destruction and creation of spatial tuning by disinhibition: $\mathrm{GABA}_{\mathrm{A}}$ blockade of prefrontal cortical neurons engaged by working memory. J Neurosci 20:485-494.

Reitboeck HJ (1983) Fiber microelectrodes for electrophysiological recordings. J Neurosci Methods 8:249-262.

Ruffo M, Postupna N, Anderson M (2001) Corticothalamic neurons to motor thalamus have low spontaneous or task related activity. Soc Neurosci Abstr 27:824.4

Schmied A, Fetz EE (1987) Activity-related changes in electrical thresholds of pyramidal tract axons in the behaving monkey. Exp Brain Res 65:352-360
Sherman SM, Guillery RW (2001) Exploring the thalamus. New York: Academic.

Sillito AM (1975) The contribution of inhibitory mechanisms to the receptive field properties of neurons in the striate cortex of the cat. J Physiol (Lond) 250:305-329.

Strick PL, Sterling P (1974) Synaptic termination of afferents from the ventrolateral nucleus of the thalamus in the cat motor cortex. A light and electron microscopy study. J Comp Neurol 153:77-106.

Swadlow HA (1988) Efferent neurons and suspected interneurons in binocular visual cortex of the awake rabbit: receptive fields and binocular properties. J Neurophysiol 59:1162-1187.

Swadlow HA (1989) Efferent neurons and suspected interneurons in S-1 vibrissa cortex of the awake rabbit: receptive fields and axonal properties. J Neurophysiol 62:288-308.

Swadlow HA (1990) Efferent neurons and suspected interneurons in S-1 forelimb representation of the awake rabbit: receptive fields and axonal properties. J Neurophysiol 63:1477-1498.

Swadlow HA (1991) Efferent neurons and suspected interneurons in second somatosensory cortex of the awake rabbit: receptive fields and axonal properties. J Neurophysiol 66:1392-1409.

Swadlow HA (1994) Efferent neurons and suspected interneurons in motor cortex of the awake rabbit: axonal properties, sensory receptive fields, and subthreshold synaptic inputs. J Neurophysiol 71:437-453.

Swadlow HA (1995) Influence of VPM afferents on putative inhibitory interneurons in S1 of the awake rabbit: evidence from cross-correlation, microstimulation, and latencies to peripheral sensory stimulation. J Neurophysiol 73:1584-1599.

Swadlow HA (1998) Neocortical efferent neurons with very slowly conducting axons: strategies for reliable antidromic identification. J Neurosci Methods 79:131-141.

Swadlow HA (2000) Descending corticofugal neurons in layer 5 of rabbit S1: evidence for potent corticocortical, but not thalamocortical, input. Exp Brain Res 130:188-194.

Swadlow HA, Waxman SG, Rosene DL (1978) Latency variability and the identification of antidromically activated units in mammalian brain. Exp Brain Res 32:439-443.

Swadlow HA, Beloozerova IN, Sirota MG (1998) Sharp, local synchrony among putative feed-forward inhibitory interneurons of rabbit somatosensory cortex. J Neurophysiol 79:567-582.

Trendelenberg W (1911) Untersuchungen uber reizlose vorubergehende Aussaltung am Zentralnervensystem. III. Die extermitaten Region der Grosshirninde. Pflügers Arch 137:515-544.

Turner RS, DeLong MR (2000) Corticostriatal activity in primary motor cortex of the macaque. J Neurosci 20:7096-7108.

Udo M, Kamei H, Matsukawa K, Tanaka K (1982) Interlimb coordination in cat locomotion investigated with perturbation. II. Correlates in neuronal activity of Deiter's cells of decerebrate walking cats. Exp Brain Res 46:438-447.

White EL (1989) Cortical circuits. Boston: Birkhauser.

Widajewicz W, Kably B, Drew T (1994) Motor cortical activity during voluntary gait modifications in the cat. II. Cells related to the hindlimbs. J Neurophysiol 72:2070-2089.

Wilson FAW, Scalaidhe SPO, Goldman-Rakic PS (1994) Functional synergism between putative $\gamma$-aminobutyrate-containing neurons and pyramidal neurons in prefrontal cortex. Pros Natl Acad Sci USA 91: 4009-4013. 